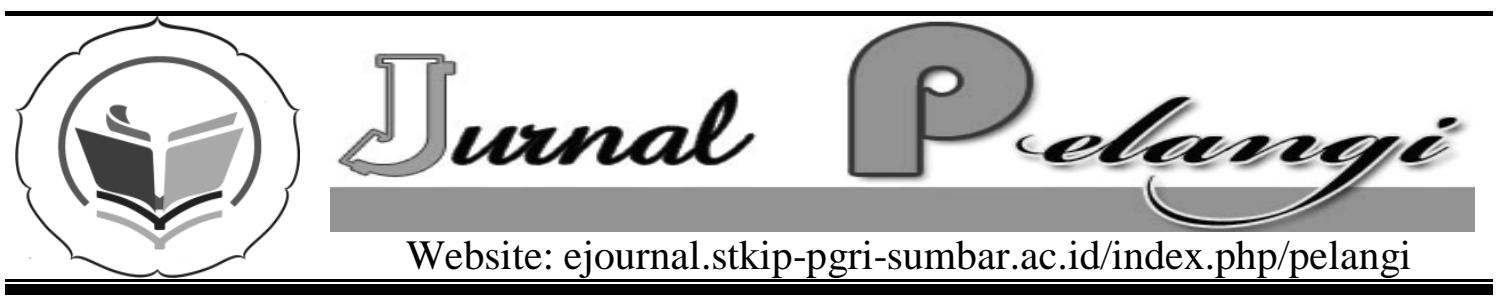

\title{
PENGARUH PENERAPAN METODE INKUIRI TERHADAP KEMAMPUAN MATEMATIKA SISWA KELAS VIII SMP NEGERI 1 PADANG-GANTING KABUPATEN TANAH DATAR
}

\author{
Rina Febriana
}

INFO ARTIKEL

Diterima:

Direview:

Disetujui:

Keywords:

treatment, inquiry, ability, mathematics

\begin{abstract}
The cause of the low understanding concepts and students problem-solving abilities in mathematics at SMP Negeri 1 Padang-ganting Tanah Datar is because the methods of teaching that is still centered on the teacher. The students were not involved actively in teaching and learning process. One of the efforts done to overcome the above problem is to use the inquiry method. The purpose of this researc is to determine: (1) Is the high group problem-solving ability in the experimental class better than the high group problem solving in the control class. (2) Is the low group problemsolving ability in the experimental class better than the low group problem solving in the control class. (3) Is the ability of understanding concept of the high group in the experiment class better than the understanding concept of high-class control group. (4) Is the ability of poor understanding concept on the experimental class better than the understanding concept of low group on the control class. This research was conducted at the eighth grade students of SMP Negeri 1 Padang-ganting school year 2010/2011. The method was Quasi Experiment with the design of the Control Group posttest design. The experiment group was treated with the inquiry method of learning and the control group with normal learning. Data were collected through the mathematic achievement test. The results showed that: (1) high group problem-solving skills in the experiment class was better than the high group problem solving in the control class, (2) the low group problem-solving ability in the experiment class was better than the low group problem solving in the control class, (3) the ability of understanding concept of the high group in the experiment class was better than the understanding concept of high-class control group. (4) the ability of poor understanding concept on the experiment class was better than the understanding concept of low group on the control class.
\end{abstract}




\section{PENDAHULUAN}

Pembelajaran matematika yang diterapkan di sekolah saat ini merupakan dasar yang sangat penting dalam keikutsertaannya mencerdaskan kehidupan bangsa. Mendidik peserta didik dalam menyongsong persaingan di era globalisasi dan kemajuan ilmu pengetahuan dan teknologi, yang diaplikasikan pada persaingan era industrialisasi pada semua aspek kehidupan yang relevan dengan kemajuan informasi dan komunikasi yang berkembang dengan pesatnya.

$$
\text { Menurut laporan Third }
$$

International Mathematics and Science Study (TIMSS) tahun 1999 yang merupakan kriteria acuan (Asmin 2002:1), rendahnya daya saing murid Indonesia di ajang international, menunjukkan betapa lemahnya kemampuan penguasaan matematika di Indonesia. (Suharta 2003:2) menyatakan bahwa, kebanyakan siswa mengalami kesulitan dalam mengaplikasikan matematika ke dalam situasi kehidupan real. Hal lain yang menyebabkan sulitnya matematika bagi siswa adalah karena pembelajaran matematika kurang bermakna. Guru dalam pembelajarannya di kelas tidak mengaitkan dengan skema yang telah dimiliki siswa dan siswa kurang diberi kesempatan untuk menemukan kembali dan mengkonstruksi sendiri ide-ide matematika.

$$
\text { Metode inkuiri yang }
$$

mensyaratkan keterlibatan aktif siswa terbukti dapat meningkatkan prestasi belajar dan sikap anak terhadap Matematika dan Sains (Haury, 2008:54). Metode inkuiri juga membantu perkembangan antara lain scientific literacy dan pemahaman proses-proses ilmiah, pengetahuan vocabulary dan pemahaman konsep, berpikir kritis, dan bersikap positif, dapat disebutkan bahwa metode inkuiri tidak saja meningkatkan pemahaman siswa terhadap konsep-konsep dalam matematika saja, melainkan juga membentuk sikap keilmiahan dalam diri siswa.

Berdasarkan hasil wawancara dengan guru matematika di SMP Negeri 1 Padang-ganting masalah dalam proses pembelajaran adalah matematika merupakan mata pelajaran yang kurang disenangi oleh siswa, rendahnya hasil matematika siswa, motivasi siswa belajar matematika masih kurang, dalam belajar siswa cenderung menghafalkan materi dan tahap-tahap penyelesaikan contoh soal. Ketika siswa dihadapkan dengan soal yang sedikit bahasanya berbeda tetapi maksud pertanyaannya sama atau sebaliknya, siswa kurang mampu menyelesaikan soal tersebut. Siswa kurang mampu mengaitkan informasi yang baru didapatnya dengan pengetahuan yang telah dimiliki. Hal ini akan mengakibatkan siswa tidak bisa menyelesaikan masalah tersebut. Dan metode belajar yang dilaksanakan oleh guru masih belum bervariasi. salah satu metode pembelajaran yang bisa mengaktifkan siswa adalah dengan menggunakan metode inkuiri, karena dalam metode ini siswa dapat menemukan konsep matematika dan memecahkan berbagai masalah dalam matematika. Oleh karena itu ingin melihat pengaruh penerapan metode inkuiri terhadap kemampuan matematika di kelas VIII SMP Negeri 1 padang-ganting. Hal ini terlihat dari persentase ketuntasan ujian semester 1 siswa kelas VIII SMP Negeri 1 Padangganting Kabupaten Tanah Datar yang dibawah SKBM 60 seperti yang terlihat dalam Tabel 1. 


$$
s^{2}=\frac{\left(n_{1}-1\right) s_{1}^{2}+\left(n_{2}-1\right) s_{2}^{2}}{n_{1}+n_{2}-1}
$$

Keterangan :

$\overline{x_{1}}=$ rata-rata kelas eksperimen

$\overline{x_{2}}=$ rata - rata kelas kontrol

$s_{1}^{2}=$ simpangan baku kelas eksperimen

$s_{2}^{2}=$ simpangan baku kelas kontrol

$n_{1}=$ jumlah siswa kelas eksperimen

$n_{2}=$ jumlah siswa kelas kontrol

Kriteria pengujiannya adalah tolak $\mathrm{H}_{\mathrm{o}}$ jika $\mathrm{t}_{\text {hitung }}>\mathrm{t}_{(1-\alpha)}$ dengan $\mathrm{df}$ $=\left(\mathrm{n}_{1}+\mathrm{n}_{2}-2\right)$ selain itu $\mathrm{H}_{\mathrm{o}}$ diterima (Sudjana 1999: 239).

Setelah
dilaksanakan
penelitian, maka bab ini
membahas hasil yang diperoleh,
yaitu tentang pengaruh penerapan
metode inkuiri terhadap kemampuan
pemahaman konsep dan kemampuan
pemecahan masalah siswa kelas VIII
SMP Negeri 1 Padang-ganting
Kabupaten Tanah Datar Tahun
pelajaran 2010/2011.

Pada gambar 1 terlihat bahwa persentase kelas eksperimen lebih besar daripada kelas kontrol, pemecahan masalah.

\section{1) Pemahaman Konsep}

Tes hasil belajar pemahaman konsep siswa di kelas eksperimen dan kelas kontrol dapat dilihat pada tabel 3.

Tabel 3

Tes hasil belajar pemahaman konsep

\begin{tabular}{|l|l|l|l|l|}
\hline Kelas & $X_{\text {maks }}$ & $X_{\min }$ & Rata-rata & Simpangan Baku \\
\hline Eksperimen & 38 & 15 & 28,57692 & 5,954313 \\
\hline Kontrol & 40 & 10 & 23,48387 & 7,196624 \\
\hline
\end{tabular}

Pada tabel 7 terlihat bahwa ratarata pemahaman konsep siswa yang menggunakan pembelajaran inkuiri lebih tinggi daripada pembelajaran konvensional. Berdasarkan data simpangan baku maka skor pemahaman konsep siswa yang menggunakan pembelajaran konvensional menyebar dibandingkan yang menggunakan metode inkuiri. Skor maksimal dan skor minimal pemahaman konsep untuk kelas eksperimen lebih tinggi dibandingkan dengan kelas kontrol.

\section{2) Pemecahan Masalah}

Tes hasil belajar pemecahan masalah siswa di kelas eksperimen dan kelas kontrol dapat dilihat pada tabel 4.

\section{Tabel 4}

Tes hasil belajar pemecahan masalah

\begin{tabular}{|l|l|l|l|l}
\hline Kelas & $X_{\operatorname{mak}}$ & $X_{\min }$ & Rata-rata & Simpangan Baku \\
\hline Eksperimen & 45 & 20 & 33,84615 & 8,161825 \\
\hline Kontrol & 45 & 10 & 27,322258 & 8,915855 \\
\hline
\end{tabular}

Pada tabel 4 terlihat bahwa ratarata pemecahan masalah siswa yang menggunakan pembelajaran inkuiri lebih tinggi daripada pembelajaran konvensional. Berdasarkan data simpangan baku maka skor pemecahan masalah siswa yang menggunakan pembelajaran konvensional menyebar dibandingkan yang menggunakan metode inkuiri.

Tes hasil belajar pemecahan masalah kelompok tinggi siswa di kelas eksperimen dan kelas kontrol dapat dilihat pada tabel 5 .

Tabel 5

Tes hasil belajar kelompok tinggi pemecahan masalah

\begin{tabular}{|l|l|l|l|l|}
\hline Kelas & $X_{\operatorname{mak}}$ & $X_{\min }$ & Rata-rata & Simpangan Baku \\
\hline Eksperimen & 45 & 40 & 43,57 & 2,44 \\
\hline Kontrol & 45 & 35 & 37,375 & 3,583195 \\
\hline
\end{tabular}

Pada tabel 5 terlihat bahwa ratarata pemecahan masalah siswa kelompok tinggi yang menggunakan pembelajaran inkuiri lebih tinggi daripada siswa kelompok tinggi pada pembelajaran 
konvensional. Berdasarkan data simpangan baku maka skor pemecahan masalah siswa yang menggunakan pembelajaran konvensional menyebar dibandingkan yang menggunakan metode inkuiri.

\section{B, Pengujian Persyaratan}

Deskripsi data hasil penelitian yang telah diuraikan pada bagian sebelumnya merupakan gambaran umum dari suatu data sampel tanpa ada kesimpulan yang dapat digeneralisasikan. Selanjutnya, agar dapat digunakan sebagai dasar pengambilan keputusan yang lebih bermakna, maka perlu dilakukan pengujian data sampel secara analitik. Sesuai dengan desain eksperimen yang digunakan dalam penelitian ini, maka uji statistik yang digunakan adalah uji perbedaan ratarata. Uji perbedaan rata-rata ini digunakan untuk membandingkan skorskor data sampel yang diperoleh kedua kelompok penelitian. Untuk menguji hipotesis yang telah dikemukakan, perlu dilakukan uji persyaratan terlebih dahulu, yaitu uji normalitas dan uji homogenitas untuk semua kelompok data.

a) Uji Normalitas

b) Uji Homogenitas Variansi

C. Pembahasan

Proses pembelajaran
metode inkuiri siswa tak han
dituntut untuk menguasai materi
pelajaran, akan tetapi bagaimana
mereka dapat menggunakan potensi
yang dimilikinya. Manusia yang
hanya menguasai pe-lajaran belum
tentu dapat mengembangkan
kemampuan berpikir secara optimal.
Sebaliknya, siswa akan dapat
mengembangkan

berpikirnya manakala ia bisa menguasai materi pelajaran. Metode inkuiri menekankan pada pencarian informasi dan pemecahan masalah yang akan berdampak pada meningkatnya keinginan dan dan ketertarikan siswa untuk ikut dalam proses pembelajaran sesuai dengan sifat inkuiri yang menekankan pada aktivitas siswa secara maksimal untuk mencari dan menemukan sesuai dengan pendapat Nurhadi (2004:43) bahwa dengan inkuiri pengetahuan dan keterampilan yang diperoleh siswa diharapkan bukan merupakan keterampilan hasil mengingat seperangkat fakta-fakta, tetapi hasil dari menemukan sendiri.

Selama proses pembelajaran berlangsung siswa mampu mengkronstruksi sendiri ataupun bersama kelompok belajarnya pengertian dari beberapa istilah yang ada dalam materi pelajaran misalnya siswa dapat merumuskan teorema pythagoras, merumuskan kebalikan teorema pythagoras, mengenal tripel pythagoras dan menentukan jenis segitiga. Hal ini berdampak baik bagi siswa dalam menyelesaikan soal-soal tes yang terkait dengan pemahaman konsep yang salah satunya seperti pada soal "teorema Pythagoras untuk segitiga siku-siku ABC dapat dirumuskan menjadi dan menentukan nilai sisi lain apabila dua sisi pada segitiga tersebut diketahui". Hal ini dapat dilihat dari jawaban siswa (M.R)

1. Hasil Belajar pada Aspek
Pemahaman Konsep

Hasil temuan di lapangan menunujukkan pemahaman konsep siswa yang menerapkan pembelajaran dengan menggunakan metode inkuiri lebih baik dari pemahaman konsep siswa dengan pembelajaran konvensional. 
Berdasarkan hasil ulangan harian siswa dan pengamatan di lapangan ditemukan bahwa dalam pembelajaran dengan metode inkuiri yang sudah dilakukan, siswa mampu menemukan konsep sendiri. Dalam lembar kerja siswa yang dikerjakan dalam setiap kali pertemuan dapat memandu dan memancing ingatan siswa terhadap apa yang telah diketahuinya kemudian memadukan materi pembelajaran yang sedang dipelajari.

Hal ini dapat dilihat dalam siswa menjawab pertanyaan yang ada dalam LKS sehingga dapat menemukan konsep sendiri (lembar jawaban LKS $\mathrm{SF})$
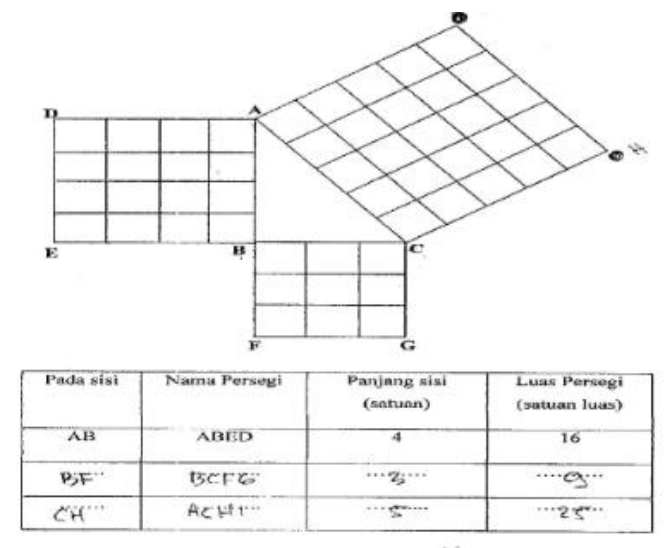

Segitiga ABC di atas merupakan negitiga . SlkM: fik:!... di titik A

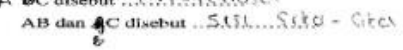

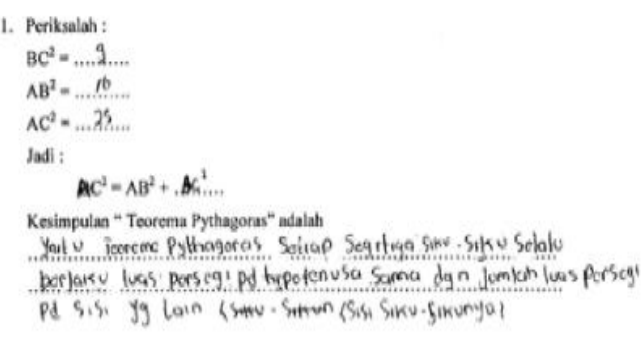

Gambar 2. Hasil jawaban LKS siswa

Padag gambar 2. terlihat bahwa dengan bantuan gambar tiga buah persegi dengan ukuran panjang sisi persegi tersebut 3 satuan, 4 satuan dan 5 satuan, siswa dapat menentukan luas persegi tersebut. Apabila persegi tersebut dihubungkan maka akan terbentuk segitiga siku-siku misalkan segitiga tersebut $\mathrm{ABC}$. Dari segitiga tersebut siswa dapat menemukan mana yang dikatakan sisi siku-siku dan sisi hipotenusa. Setelah itu siswa tersebut dapat menyimpulkan apa yang dikatakan dengan teorema Pythagoras.

Dalam pembelajaran dengan metode inkuiri, siswa melakukan kegiatan penemuan dengan teman sekelompoknya. Melalui pembelajaran dengan metode inkuiri siswa dapat lebih leluasa berdiskusi dengan sekelompoknya dengan demikian mereka dapat lebih memahami konsep yang ada dengan sebaik-baiknya. Proses penemuan dilakukan secara berkelompok, bekerja sama secara aktif dan shering dengan masing- masing anggota dalam kelompok dengan bantuan guru. Setiap anggota kelompok harus dapat mengkonstruksi pengetahuan, menyadari bahwa setiap anggota kelompok saling ketergantungan yang positif satu sama lain, mempunyai tanggung jawab individual terhadap keberhasilan kelompok dan memiliki peluang yang sama untuk berhasil. Dengan demikian konsep-konsep matematika dapat dipahami oleh setiap anggota kelompok dalam suasana yang kondusif sehingga dapat bertahan dalam struktur kognitif siswa. Sesuai dengan pendapat Vygotsky (Nur Asma, 2008:38) yang mengatakan bahwa interaksi sosial memacu timbulnya ide baru dan memperkaya pengembangan intelektual siswa.

\section{Hasil Belajar pada Aspek \\ Kemampuan Pemecahan Masalah}

Hasil temuan untuk aspek kemampuan pemecahan masalah adalah kemampuan pemecahan masalah siswa yang menerapkan metode inkuiri lebih 
baik kemampuan pemecahan masalah siswa dengan pembelajaran konvensional. Branca (1980:3-7) menginterpretasikan pemecahan masalah dalam tiga hal, yaitu, pemecahan masalah dipandang sebagai tujuan, proses dan keterampilan dasar. Dalam penelitian ini pemecahan masalah dijadikan sebagai tujuan yang hendak dicapai melalui proses belajar mengajar.

\section{KESIMPULAN}

Penelitian ini merupakan penelitian yang membandingkan dua metode pembelajaran, yaitu metode inkuiri dan metode konvensional. Penulis dapat menarik beberapa kesimpulan yaitu.

1. Pemahaman konsep kelompok tinggi siswa yang diajar dengan metode inkuiri lebih baik dari kelompok tinggi siswa yang diajar secara konvensional.

2. Pemahaman konsep kelompok rendah siswa yang diajar dengan metode inkuiri lebih baik dari pemahaman konsep kelompok rendah siswa yang diajar secara konvensional.

3. Pemecahan masalah kelompok tinggi siswa yang diajar dengan metode inkuiri lebih baik dari pemahaman konsep kelompok tinggi siswa yang diajar secara konvensional.

4. Pemecahan masalah kelompok rendah siswa yang diajar dengan metode inkuiri lebih baik dari pemecahan masalah kelompok rendah siswa yang diajar secara konvensional.

Berdasarkan kesimpulan di atas maka penulis mengemukakan beberapa saran sebagai berikut.

5. Instrumen yang digunakan dalam penelitian ini agar diperbanyak sehingga dapat mengukur kemampuan siswa secara individu.
6. Soal tes untuk masing-masing aspek kognitif agar diperbanyak agar lebih detil mengukur setiap indikatornya.

7. Bagi guru yang menerapkan metode inkuiri, agar membuat perencanaan yang matang tentang pembagian waktu ketika melaksanakan proses pembelajaran, apa yang dilakukan siswa dan model ini cocok diterapkan pada materi yang bagaimana.

\section{DAFTAR PUSTAKA}

Haury, L. David. 1993. Teaching Science Through Inquiry. Columbus, OH: ERIC Clearinghouse for Science, Mathematics, and Environment Education. (ED359048). Muliyardi. 2002. Strategi Pembelajaran Matematika. Padang: Universitas Negeri Padang.

Nurhadi dkk. 2002. Pembelajaran Kontekstual .Depdiknas Dikposmen: Jakarta. 